\title{
The Ctenophore Mnemiopsis leidyi Has a Flow-Through System for Digestion with Three Consecutive Phases of Extracellular Digestion
}

\author{
Dirk Bumann \\ Gabriela Puls \\ Marine Biological Laboratory, Woods Hole, \\ Massachusetts 02543
}

Accepted by C.P.M. 3/15/96

\begin{abstract}
The ctenophore (comb jelly) Mnemiopsis leidyi is a periodically abundant and voracious predator in U.S. coastal waters. Mnemiopsis leidyi is especially competitive at high prey concentrations because of its very efficient extracellular digestion. We investigated the functional basis for these outstanding digestion capabilities. Extracellular digestion takes place in the pharynx and consists of three distinct and consecutive phases. The three phases take place in different regions of the pharynx so that various prey items can be treated simultaneously in each phase. The first phase is acidic, while the second and the third are alkaline. Extracellular digestion is completed by ciliary currents that mechanically disrupt the predigested food. Bulky indigestible food fragments are expelled through the mouth. Except for a small area, the paths for ingestion and egestion are separate. Hence, both ingestion and egestion can occur simultaneously. The flattened and elongated shape of the pharynx provides the morphological basis for this flow-through system with various regions for different digestive treatments of the food. This system is highly elaborated compared with those of other lower invertebrates and allows for an efficient, fast, and simultaneous digestion of many prey items, which accounts for the outstanding feeding capabilities of M. leidyi.
\end{abstract}

\section{Introduction}

The lobate ctenophore (comb jelly) Mnemiopsis leidyi A. Agassiz is a voracious and environmentally important predator of all kinds of zooplankton. It can control zooplankton abundance and, consequently, phytoplankton abundance (Burell and van Engel 1976; Reeve and Walter 1978; Kremer 1979;

Physiological Zoology 70(1):1-6. 1997. (c) 1997 by The University of Chicago. All rights reserved. 0031-935X/97/7001-95135\$02.00
Deason and Smayda 1982). Moreover, M. leidyi feeds on fish eggs and larvae and can thus diminish fish populations as both a predator and a food competitor (Arai 1988; Monteleone and Duguay 1988; Govoni and Olney 1991; Houde et al. 1994; Purcell et al. 1994). Mnemiopsis leidyi is an especially competitive predator at high levels of zooplankton abundance (Reeve et al. 1978) because its ingestion rate increases in proportion with food concentration even up to very abundant food levels (Reeve et al. 1989), whereas in most other plankton predators, ingestion rates level off at a certain food concentration (Reeve 1980). Both nitrogen metabolism and respiration are rather low but within the range of many other marine invertebrates (Kremer 1982; Schneider 1990, 1992) and cannot therefore be related to the outstanding feeding capabilities of $M$. leidyi. Instead, extracellular digestion appears to be the basis for the capability to process large amounts of plankton food. Mnemiopsis leidyi digests plankton food faster than chaetognaths or scyphomedusae and, in contrast to scyphomedusae, can digest bivalve veligers (Reeve 1980; Purcell et al. 1991). However, ctenophores have digestive enzyme activities comparable to those of other lower invertebrates (Fankboner and Reid 1978; Hoeger and Mommsen 1984), and it is not yet evident how the efficient extracellular digestion is achieved. In this report, we investigate the physiology of digestion of $M$. leidyi to obtain a better understanding of the functional basis for its feeding capabilities.

\section{Material and Methods}

Mnemiopsis leidyi was collected from the shore at Woods Hole, Massachusetts, with plastic jars, transferred to filtered $(0.2 \mu \mathrm{m})$ seawater (SW), and kept in 8 -L buckets at $19^{\circ} \pm 2^{\circ} \mathrm{C}$.

In order to study digestion, individuals were pinned down with needles to the bottom of a 1-L glass bowl containing a layer of Sylgar at the bottom. Artemia (brine shrimp) nauplii were used as prey. Nauplii were pipetted beneath the lobes of $M$. leidyi, and ingestion, digestion, and egestion were followed with a dissecting scope. The position of the prey in $M$. leidyi was determined to the nearest $0.1 \mathrm{~mm}$ for 10 individuals with a calibrated scale in the ocular. To obtain data for high ingestion frequencies, each $M$. leidyi was fed an Artemia nauplius every $3 \mathrm{~min}$. The number of nauplii in different parts of the pharynx was recorded (five replicates). To trace the digestion of a specific prey at this high ingestion frequency, single stained nauplii (0.02\% Evans Blue for $24 \mathrm{~h}$ ) were occasionally fed among unstained nauplii (four replicates each for three $M$. leidyi). 
For mass feeding, $M$. leidyi was placed in a beaker with 800 $\mathrm{mL}$ filtered SW containing 20 Artemia $\mathrm{mL}^{-1}$. After $10 \mathrm{~min}$ of feeding, M. leidyi was transferred to filtered SW and observed with a dissecting scope (five replicates).

To observe $\mathrm{pH}$ changes during digestion, Artemia nauplii were stained (Jennings 1974 ) for $48 \mathrm{~h}$ with $0.02 \%$ solutions (in filtered SW) of the $\mathrm{pH}$ indicators phenol red ( $\mathrm{pK} 7.9$; Conn 1961), bromo thymol blue (pK 7.0), or bromo cresol purple (pK 6.3) and washed for $2 \mathrm{~h}$ with several changes of fresh, filtered SW prior to feeding to $M$. leidyi. The dyes accumulated in the gut of Artemia as observed previously (Croghan 1958). In nauplii stained with phenol red, this region appeared bright red as in previous studies (Croghan 1958), which indicates a $\mathrm{pH}$ of 7.9 or higher in the gut of Artemia. No independent measurements of the gut $\mathrm{pH}$ in Artemia exist (Blust et al. 1988), but we estimate that it is slightly more alkaline than the $\mathrm{pH}$ of gut contents of other crustaceans, which is in the range 4.77.6 (Vonk 1960; Dall and Moriarty 1983). Artemia nauplii are continuously pumping SW through their gut (Croghan 1958; Wolvekamp and Waterman 1960); hence, their $\mathrm{pH}$ might more closely reflect the $\mathrm{pH}$ of $\mathrm{SW}$ (8.2). After ingestion of dyed Artemia by M. leidyi (five replicates per indicator), the color of the dye indicated the $\mathrm{pH}$ during digestion. However, the changes in $\mathrm{pH}$ may be retarded in the gut of the prey compared with its body surface, and the $\mathrm{pH}$ changes might also be smaller because of the presence of buffering groups of the prey. Therefore, the $\mathrm{pH}$ indicators were used only to obtain a qualitative estimate of $\mathrm{pH}$ changes during digestion.

\section{Results}

All ctenophores have a similar gastrovascular system (Chun 1880; Mayer 1912; Main 1928; Schulze-Roebbecke 1984). A mouth opens into a flattened and elongated pharynx, or stomodeum (Fig. 1). In the aboral third of the pharynx, there are so-called pharyngeal folds ("Magenwülste"; Chun 1880), which are barely visible $\mathrm{U}$-shaped lines. At the end of the pharynx a small esophagus leads into the stomach, or funnel. From the stomach, canals branch off and run through most of the body beneath the comb rows, along the pharynx, to the tentacles and the aboral pole. The aboral canals open to the exterior through anal pores.

In Mnemiopsis leidyi, captured prey was transported through the mouth into the pharynx (Fig. 1), where extracellular digestion occurred mainly as observed previously (Main 1928; Schulze-Roebbecke 1984; Hernandez-Nicaise 1991). Recordings of the time-dependent position of the prey revealed three separate phases in the pharynx for all $10 \mathrm{M}$. leidyi tested (Fig. 2). First (phase 1), prey was transported into the center of the pharynx with a velocity of $1-2 \mathrm{~mm} \mathrm{~min}^{-1}$ to an area close to the pharyngeal folds, where it rested for 15-25 min (median, $20 \mathrm{~min}$ ). During this phase, Artemia became inactive (after a median time of $10 \mathrm{~min}$ ). Second (phase 2), nearly intact prey was then transported to the area enclosed by the pharyngeal folds, where it remained for 3-12 min (median, 7 min). Finally (phase 3 ), the prey was transported to the esophagus, where it was disrupted by strong ciliary countercurrents and compound cilia with specialized heads apparently adapted for mechanical destruction of food fragments (S. Tamm, personal communication). These compound cilia (ec in Fig. 1) occur in high density near the esophagus. Particles smaller than $30 \mu \mathrm{m}$ entered the stomach and were distributed in the canal system, where endocytosis and intracellular digestion occurred as observed previously (Komai 1922). Freshly collected M. leidyi sometimes expelled debris accumulating in the canal system through the anal pores at the end of the aboral canals, as has been observed earlier (Main 1928). This could be the remains of intracellular digestion. In contrast, bulky indigestible food fragments (mainly the exoskeleton of the prey) did not enter the stomach or the canal system but were retained by the esophagus, transported along the edges of the pharynx with a velocity of $2-5 \mathrm{~mm} \mathrm{~min}^{-1}$, and finally expelled through the mouth (Main 1928).

Single Artemia nauplii stained with $\mathrm{pH}$ indicators were used to qualitatively follow the $\mathrm{pH}$ during digestion. From a $\mathrm{pH}$ higher than 7.9 in Artemia in SW, the pH dropped below 6.3 within $20 \mathrm{~min}$ (median of five replicates) of ingestion, in good agreement with the acidic $\mathrm{pH}$ previously measured for the pharyngeal juice of the ctenophore Pleurobrachia bachei (Fankboner and Reid 1978). After entering the area enclosed by the pharyngeal folds, the $\mathrm{pH}$ rose within $5 \mathrm{~min}$ to values above 7.9, where it remained throughout phase 2 and phase 3.

These various phases also occurred when $M$. leidyi was fed with Artemia nauplii at a frequency of $20 \mathrm{~h}^{-1}$. After about 1 $\mathrm{h}$ of feeding, steady state conditions for digestion times and abundance of prey in the different phases were reached. At these steady state conditions, the duration of phase 1 was significantly greater than with feeding with a single nauplius (median, 43 min; Mann-Whitney $U$-test, $U=0, P<0.05$; Siegel 1956), while the duration of phase 2 was not significantly different (median, $12 \mathrm{~min}$ ). At steady state conditions, $14-18$ nauplii were in phase 1 , while zero to three nauplii were in phases 2 and 3 . The durations for phase 1 and 2 and the relative abundance of prey in these phases indicate that phase 1 is the ratelimiting step of extracellular digestion. In all five individuals observed, the central part of the pharynx formed pockets extruding on both sides of the pharynx (Fig. $1 B$ ). The path for ingestion in the center of the pharynx and the path for egestion of indigestible food fragments along the edges of the pharynx were separated by the area in between, where the epithelium of both sides of the pharynx was in close contact (Fig. 1B). In two of five M. leidyi observed, undigested nauplii from phases 1 or 2 were occasionally transported along the edges of the pharynx toward the mouth and expelled (Fig. 1A), as has previously been observed (Reeve et al. 1978; Kremer and Reeve 1989). The main force for the transport along the pharynx 


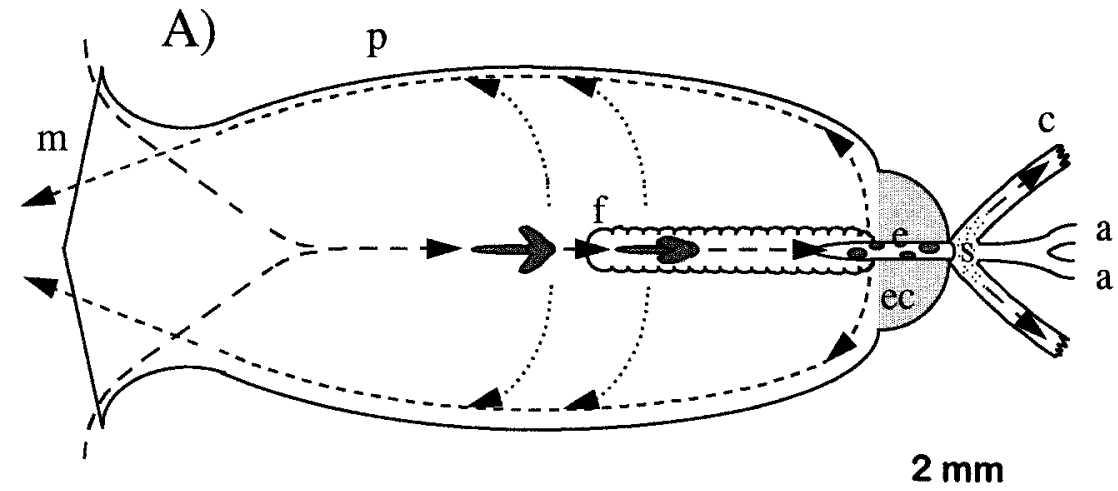

B)

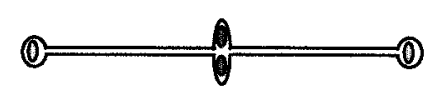

Figure 1. Gastrovascular system of the ctenophore Mnemiopsis leidyi. $A$, Ingested prey during the three phases of extracellular digestion (phase 1, close to the pharyngeal folds; phase 2, in the pharyngeal folds; phase 3 , in the esophagus) and small food fragments generated by the extracellular digestion in the canal system. The dashed arrows indicate the paths for ingestion and egestion, and the dotted lines indicate shortcuts used during superfluous feeding; $a$, anal pores; $c$, canal system; $e$, esophagus; $e c$, area close to the esophagus with a high density of cilia; $f$, pharyngeal folds; $m$, mouth; $p$, pharynx; and $s$, stomach. $B$, Cross section of the pharynx in the area of phase 1 . The central part of the pharynx forms two pockets on both sides of the pharynx where food is digested. Indigestible food fragments are transported along the edges of the pharynx toward the mouth. The pharyngeal epithelium of both sides of the pharynx in the intermediate region is in close contact and thereby seals off the paths for ingestion and egestion.

seemed to be provided by motile cilia. Pharynx contractions were observed in all five individuals studied but apparently had little influence on food transport.

On mass feeding, $M$. leidyi ingested 50-100 Artemia nauplii in $10 \mathrm{~min}$. Most of the nauplii stayed active and were finally transported along the edges of the pharynx toward the mouth (Fig. 1A) and expelled alive after a median time of $65 \mathrm{~min}$. Up to this point no $\mathrm{pH}$ changes could be detected. After expulsion, the remaining few nauplii (two to eight) were normally processed.

\section{Discussion}

Ctenophores are lower invertebrates at a diploblastic level of organization (Hyman 1940). Recent molecular evidence suggests that ctenophores were the first metazoans to diverge after the sponges (Kobayashi et al. 1993; Wainwright et al. 1993). Despite the low level of organization and the early divergence of the phylum, the ctenophore Mnemiopsis leidyi has an elaborate flow-through system for digestion with three consecutive extracellular phases compared with only one extracellular phase in cnidarians and flatworms (Gardiner 1972; Jennings 1974; Sebens 1987). This elaborate extracellular digestion appears to be the functional basis for the unusually fast and efficient feeding.

The spatial separation of the three phases of extracellular digestion is made possible by the elongated shape of the pharynx typical of ctenophores (Chun 1880). Extracellular digestion that includes both acidic and alkaline phases, as observed for M. leidyi, is common for higher metazoans but exceptional for lower invertebrates (Gardiner 1972; Jennings 1974; Sebens 1987). Fankboner and Reid (1978) measured a $\mathrm{pH}$ of 5.3 for the pharyngeal juice of the ctenophore Pleurobrachia bachei. Since they combined the fluid from all regions of the pharynx, they did not notice the heterogeneity observed in our study. Differing $\mathrm{pH}$ values result in different conformations of protonable biopolymers and therefore expose more potential cleavage sites for an attack by digestive enzymes. Hydrolytic enzymes with either acidic or alkaline $\mathrm{pH}$ optima have been found in ctenophores (Fankboner and Reid 1978; Hoeger and Mommsen 1984) and are likely to function in sequence during phases 1-3. A chitinase with an acidic optimum has been observed in crude extracts of Pleurobrachia pileus (Hoeger and Mommsen 1984), which suggests that the chitinous exoskeleton of its predominantly crustacean prey (Greve 1981) is attacked during the acidic phase 1 . Such a digestion of the exoskeleton in phase 1 would expose interior parts of the prey for the action of other digestive enzymes early in digestion, thereby enhancing their efficiency.

Under conditions of excess of food, $M$. leidyi expelled most of the undigested food, thereby decreasing its assimilation efficiency (Reeve et al. 1989). A conflict between ingestion and egestion (Kremer and Reeve 1989) is not the reason for this expulsion, since the food is expelled long before any of it has been processed for egestion. The presence of too many $\mathrm{pH}-$ buffering groups on the prey could prevent acidification. Most of the food might be expelled to restrict the amount of food to manageable quantities. Under natural conditions, prey 


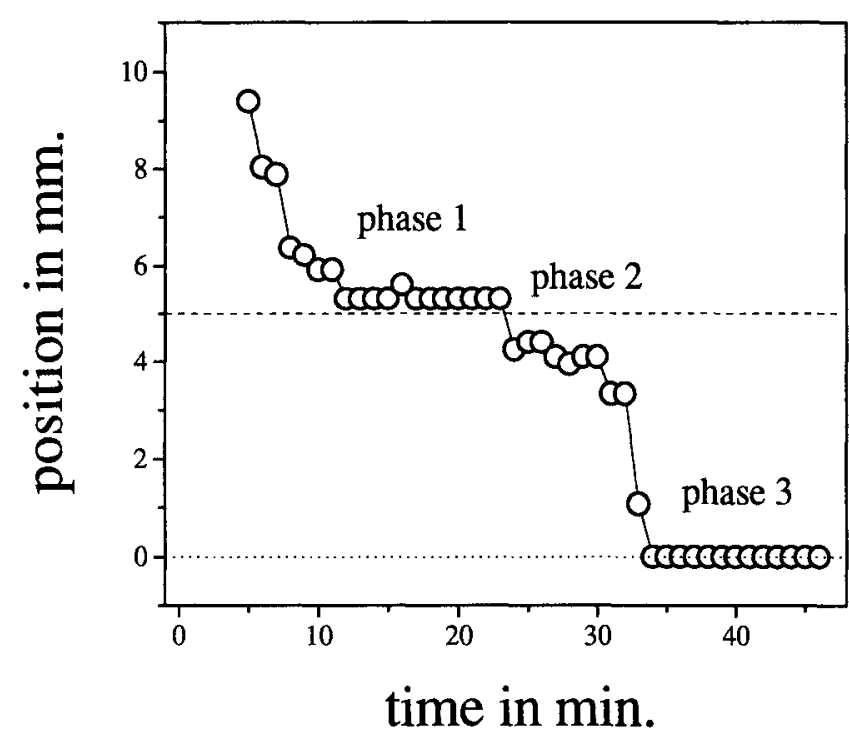

Figure 2. Time-dependent position of prey in the pharynx of Mnemiopsis leidyi. The distance of a single ingested Artemia nauplius to the esophagus was measured along the longitudinal axis of $M$. leidyi. The prey is held at three different positions so that extracellular digestion proceeds in three distinct phases. The dashed line represents the position of the pharyngeal folds, and the dotted line represents the position of the esophagus.

abundance rarely reaches the level at which superfluous feeding by $M$. leidyi occurs (Reeve et al. 1989).

Pores in the gastrovascular system of $M$. leidyi lead to the exterior environment, as in many animals with a "blind-ending gut" (Hyman 1940; Gardiner 1972; Werner 1984; Arai and Chan 1989; Schlichter 1991). True flow-through systems have occasionally been evolved in corals (Schlichter 1991), but most ctenophores, cnidarians, and platyhelminthes use their mouths as the main excretion site despite the frequent occurrence of pores and the obvious advantages of a flow-through system (Gardiner 1972). In M. leidyi, the anal pores function to excrete intracellularly digested residues (Main 1928), but large indigestible food fragments are expelled through the mouth. The reason for this could be related to the narrow canals extending through the whole body that function to distribute the small food fragments generated by extracellular digestion. These narrow canals might easily be clogged by large food fragments. It is possible that, for this reason, large food fragments do not enter the canal system but are retained by the esophagus, which functions as a filter. Therefore, the only path for the expulsion of large indigestible food fragments is through the mouth. Similar conflicts between excretion and circulation in narrow canals have been proposed as the reason for the differential use of the mouth and various pores in the hydromedusa $A e-$ quora victoria (Arai and Chan 1989).

Using the mouth as a major excretion site could cause conflicts between ingestion and egestion (Kremer and Reeve 1989). Except for a small crossing area, however, $M$. leidyi has spatially separate paths for ingestion and egestion so that both processes can take place simultaneously. Separate paths for ingestion and egestion have also been observed in scypho- and cubomedusae (Larson 1976). In M. leidyi, the separation is achieved in the flattened pharynx. In most regions of the pharynx, the epithelia contact each other and thereby seal off the different paths in the center and along the edges. Hence, the shape of the pharynx provides the morphological basis for a flow-through system for the extracellular digestion, although the mouth is used both for ingestion and egestion. The pharynx is widest in the area where phase 1 occurs, thus allowing for separated paths even when many food items accumulate during phase 1 . This is important since phase 1 is the rate-limiting step of extracellular digestion. The paths for ingestion and egestion can also be shortcut in case of superfluous feeding. Sea anemones have a flattened pharynx that similarly provides spatially separate paths for in- and outgoing water currents (Hyman 1940).

In conclusion, the shape of the pharynx in $M$. leidyi provides the morphological basis for a flow-through system with various regions for different treatments of the food. This allows for an efficient, fast, and simultaneous digestion of many prey items. The morphology of the gastrovascular system is very similar among all ctenophores (Chun 1880; Harbison 1985). Therefore, it is possible that other ctenophore species of great ecological importance (Greve 1981) have a digestive physiology similar to that of $M$. leidyi.

\section{Acknowledgments}

Financial support by the Deutsche Forschungsgemeinschaft in form of a postdoctoral fellowship to D.B. ( $\mathrm{Bu} \mathrm{971/-1)} \mathrm{is} \mathrm{grate-}$ fully acknowledged. We thank $H$. Chikarmane, R. Harbison, P. Kremer, A. Kuzirian, B. Lowe, and L. Madin for helpful discussions and support and especially S. Tamm for allowing us to cite his results prior to publication.

\section{Literature Cited}

Arai M.N. 1988. Interactions of fish and pelagic coelenterates. Can. J. Zool. 66:1913-1927.

Arai M.N. and I.M. Chan. 1989. Two types of excretory pores in the hydrozoan medusa Aequora victoria (Murbach and Shearer, 1902). J. Plankton Res. 11:609-614.

Blust R., A. van Der Linden, E. Verheyen, and W. Decleir. 1988. Effect of $\mathrm{pH}$ on the biological availability of copper to the brine shrimp Artemia franciscana. Mar. Biol. 98:3138.

Burell V.G. and W.A. van Engel. 1976. Predation by and distribution of a ctenophore, Mnemiopsis leidyi A. Agassiz, in the York River Estuary. Estuarine Coastal Mar. Sci. 4:235-242.

Chun C. 1880. Die Ctenophoen des Golfes von Neapel und der angrenzenden Meeres-Abschnitte. Fauna und Flora des Golfes von Neapel 1. Engelmann, Leipzig. 
Conn H.J. 1961. Biological Stains. Williams \& Wilkins, Baltimore.

Croghan P.C. 1958. The mechanism of osmotic regulation in Artemia salina (L.): the physiology of the gut. J. Exp. Biol. 35:243-249.

Dall W. and D.J.W. Moriarty. 1983. Functional aspects of nutrition and digestion. Pp. 215-261 in L.H. Mantel, ed. Internal Anatomy and Physiological Regulation. Academic Press, New York.

Deason E.E. and T.J. Smayda. 1982. Experimental evaluation of herbivory in the ctenophore Mnemiopsis leidyi relevant to ctenophore-zooplankton-phytoplankton interactions in Narragansett Bay, Rhode Island, USA. J. Plankton Res. 4:219-236.

Fankboner P.V. and R.G.B. Reid. 1978. Protein digestion in the sea gosberry Pleurobrachia bachei A. Agassiz (Ctenophora: Tentaculata). Experentia 34:728-729.

Gardiner M. 1972. The Biology of Invertebrates. McGraw-Hill, New York.

Govoni J.J. and J.E. Olney. 1991. Potential predation on fish eggs by the lobate ctenophore Mnemiopsis leidyi within and outside the Chesapeake Bay plume. Fisheries Bull. 89:181186.

Greve W. 1981. Invertebrate predator control in a coastal marine ecosystem: the significance of Beroe gracilis (Ctenophora). Kieler Meeresforschungen 5:211-217.

Harbison G.R. 1985. On the classification and evaluation of the ctenophora. Pp. 78-100 in S. Conway Morris, J.D. George, and R. Gibson, eds. The Origins and Relationships of Lower Invertebrates. Clarendon, Oxford.

Hernandez-Nicaise M.-L. 1991. Ctenophora. Pp. 359-418 in F.W. Harrison and J.A. Westfall, eds. Placozoa, Porifera, Cnidaria, and Ctenophora. Vol. 2 of Microscopy of Invertebrates. Wiley, New York.

Hoeger U. and T.P. Mommsen. 1984. Hydrolytic enzymes in the two North Sea ctenophores Pleurobrachia pileus and Beroe gracilis. Marine Biol. 81:123-130.

Houde E.D., J.C. Gamble, S.E. Dorsey, and J.H. Cowan, Jr. 1994. Drifting mesocosms: the influence of gelatinous zooplankton on mortality of bay anchovy, Anchoa mitchilli, eggs and yolk-sac larvae. Int. Counc. Exploration Sea J. Mar. Sci. 51:383-394.

Hyman L.H. 1940. The Invertebrates: Protozoa through Ctenophora. McGraw-Hill, New York.

Jennings J.B. 1974. Digestive physiology of the turbellaria. Pp. 173-197 in N.W. Riser and M.P. Morse, eds. Biology of the Turbellaria. McGraw-Hill, New York.

Kobayashi M., M. Takahashi, H. Wada, and N. Satoh. 1993. Molecular phylogeny inferred from sequences of small subunit ribosomal DNA supports the monophyly of the metazoa. Zool. Sci. 10:827-833.

Komai T. 1922. Studies on Two Aberrant Ctenophores, Coeloplana and Gastrodes. Komai, Kyoto.
Kremer P. 1979. Predation by the ctenophore Mnemiopsis leidyi in Narragansett Bay, Rhode Island. Estuaries 2:97105.

- 1982. Effect of food availability on the metabolism of the ctenophore Mnemiopsis mccradyi. Mar. Biol. 71:149156.

Kremer P. and M.R. Reeve. 1989. Growth dynamics of a ctenophore (Mnemiopsis) in relation to variable food supply. II. Carbon budgets and growth model. J. Plankton Res. 11:553574.

Larson R.J. 1976. Cubomedusae: feeding, functional morphology, behaviour and phylogenetic position. Pp. 237-246 in G.O. Mackie, ed. Coelenterate Ecology and Behavior. Plenum, New York.

Main R.J. 1928. Feeding mechanism of Mnemiopsis. Biol. Bull. 55:69-78.

Mayer A.G. 1912. Ctenophores of the Atlantic Coast of North America. Publ. Carnegie Inst. Washington 162:1-58.

Monteleone D.M. and L.E. Duguay. 1988. Laboratory studies of predation by the ctenophore Mnemiopsis leidyi on the early stages in the life history of the bay anchovy, Anchoa mitchilli. J. Plankton Res. 10:359-372.

Purcell J.E., F.P. Cresswell, D.G. Cargo, and V.S. Kennedy. 1991. Differential ingestion and digestion of bivalve larvae by the scyphozoan Chrysaora quinquecirrha and the ctenophore Mnemiopsis leidyi. Biol. Bull. 180:103-111.

Purcell J.E., D.A. Nemazie, S.E. Dorsey, E.D. Houde, and J.C. Gamble. 1994. Predation mortality of bay anchovy Anchoa mitchilli eggs and larvae due to scyphomedusae and ctenophores in Chesapeake Bay. Mar. Ecol. Prog. Ser. 114:47-58.

Reeve M.R. 1980. Comparative experimental studies on the feeding of chaetognaths and ctenophores. J. Plankton Res. 2:381-393.

Reeve M.R., M.A. Syms, and P. Kremer. 1989. Growth dynamics of a ctenophore (Mnemiopsis) in relation to variable food supply. I. Carbon biomass, feeding, egg production, growth and assimilation efficiency. J. Plankton Res. 11:535-552.

Reeve M.R. and M.A. Walter. 1978. Nutritional ecology of ctenophores: a review of recent research. Adv. Mar. Biol. 15:249-287.

Reeve M.R., M.A. Walter, and T. Ikeda. 1978. Laboratory studies of ingestion and food utilization in lobate and tentaculate ctenophores. Limnol. Oceanogr. 23:740-751.

Schlichter D. 1991. A perforated gastrovascular cavity in the symbiotic deep-water coral Leptoseris fragilis: a new strategy to optimize heterotrophic nutrition. Helgoländer Meeresuntersuchungen 45:423-443.

Schneider G. 1990. A comparison of carbon based ammonia excretion rates between gelatinous and non-gelatinous zooplankton: implications and consequences. Mar. Biol. 106:219-225.

. 1992. A comparison of carbon-specific respiration 
rates in gelatinous and non-gelatinous zooplankton: a search for general rules in zooplankton metabolism. Helgoländer Meeresuntersuchungen 46:377-388.

Schulze-Roebbecke A.C. 1984. Functional morphology of Bolinopsis infundibulum (Ctenophora). Helgoländer Meeresuntersuchungen 38:47-64.

Sebens K.P. 1987. Coelenterata. Pp. 55-120 in T.J. Pandian and F.J. Vernberg, eds. Animal Energetics. Vol. 1. Academic Press, San Diego, Calif.

Siegel S. 1956. Nonparametric Statistics for the Behavioral Sciences. McGraw-Hill, New York.

Vonk H.J. 1960. Digestion and metabolism. Pp. 291-316 in
T.H. Waterman, ed. Metabolism and Growth. Vol. 1 of The Physiology of Crustacea. Academic Press, New York.

Wainwright P.O., G. Hinkle, M.L. Sogin, and S.K. Stickel. 1993. Monophyletic origins of the metazoa: an evolutionary link with fungi. Science 260:340-342.

Werner B. 1984. Cnidaria. Pp. 11-302 in H.-E. Gruner, ed. Wirbellose Tiere. Vol. 1 of Lehrbuch der speziellen Zoologie. Fischer, Jena.

Wolvekamp H.P. and T.H. Waterman. 1960. Respiration. Pp. 35-100 in T.H. Waterman, ed. Metabolism and Growth. Vol. 1 of The Physiology of Crustacea. Academic Press, New York. 